\title{
LA CULTURA POLÍtICA PREMOdERNA Y LA CARENCIA DE DEMOCRACIA. LA VIOLENCIA EN COLOMBIA COMO EXPRESIÓN DEL ÁMBITO TRADICIONAL.
}

\author{
H. C. F. Mansilla
}

Real Academia Española

Academia de Ciencias de Bolivia

Academia Boliviana de la Lengua

Resumen.- El potencial de la violencia política y las formas específicas de sus manifestaciones en Colomibia sólo pueden ser explicadas adecuadamente si se incluyen en el análisis la dimensión de la cultura del autoritarismo y sus características premodernas. Las causas de la violencia política pueden ser calificadas de múltiples: la destrucción del tejido social tradicional, la presión demográfica, las grandes migraciones internas, las expectativas de progreso individual, la debilidad de las instituciones y la democratización incompleta. Los movimientos guerrilleros se aprovecharon de estos factores, pero no supieron brindar a la población una alternativa moderna, realista y creíble.

Palabras clave: autoritarismo, Colombia, conservadurismo, ELN, FARC, guerrillas, M-19.

\section{Premodern Political Cultural and Absence of Democracy. Colombia's Violence as a Expression of the Traditional Environment}

Abstract.- The potential of political violence and the specific forms of its displays in Colombia cannot be duly analised without considering the dimension of the authoritarian culture and their premodern features. The causes of violence are many: the destruction of traditional social webs, demographic pressures, the frailty of institutions, the large intern migratory movements, and the uncompleted democratization process. Guerrilla movements derived profit from these factors, but they failed to exhibit a modern, realistic and plausible alternative for the population.

Key words: authoritarianism, Colombia, conservatism, ELN, FARC, guerrilla, M-19.

\section{Preliminares}

El presente texto se basa ante todo en testimonios y esbozos teóricos surgidos en Colombia en torno a la llamada cultura política de la violencia, cuya especificidad e intensidad constituyen un tema muy controvertido'. También considero algunos intentos interpretativos de autores extranjeros

\footnotetext{
'Después de analizar la constelación supranacional en perspectiva comparada, el notable historiador británico Malcolm Deas, por ejemplo, pone en duda que la violencia política colombiana sea particularmente intensa y específica, es decir determinante de una supuesta identidad nacional colombiana que estuviera inmune al paso del tiempo. Cf. Malcolm Deas, Canjes violentos: reflexiones sobre la violencia política en Colombia, en: Malcolm Deas / Fernando Gaitán Daza, Dos ensayos especulativos sobre la violencia en Colombia, Bogotá: FONADE / DNP 1995, pp. 1-86.
} 
que se han destacado por su penetración analítica y la plausibilidad de sus apreciaciones a largo plazo2. Quisiera enfatizar de entrada la excelente calidad de los escritos colombianos aquí mencionados. Estos análisis combinaron tempranamente el espíritu crítico - no plegarse a las modas intelectuales del momento, por más vigorosas que estas parecieran ser -, con la utilización adecuada de datos empírico-documentales y con el conocimiento del último desarrollo de las ciencias sociales a nivel internacional. Me apoyo en publicaciones que han estudiado la época de 1948 a 1990, periodo delimitado por el comienzo de la violencia armada a gran escala (el Bogotazo de abril de 1948) y por el principio de la declinación de la misma. En marzo de 1990 se autodisolvió el Movimiento Revolucionario 19 de Abril (M-19); en ese mismo año colapsó el Ejército Popular de Liberación (EPL) y emergieron síntomas que anunciaban la disminución del entusiasmo, sobre todo juvenil, a favor de las organizaciones guerrilleras. Aunque no era una novedad, por entonces se hizo pública la notable magnitud de la imbricación de los movimientos guerrilleros sobrevivientes en el narcotráfico y en otras actividades financieramente lucrativas ${ }^{3}$ (secuestros, extorsiones, robos, reclutamiento forzoso de menores de edad), actividades que no concuerdan muy bien con la tradicional ética revolucionaria y con las pretensiones socialistas de esos grupos. Asimismo en 1991, después de muchas décadas, Colombia se dotó de una nueva Constitución Política, la cual significó un "acuerdo consensual" 4 de amplio alcance entre diferentes sectores políticos que anteriormente habían estado en contienda permanente. Se puede argüir, por supuesto, que una constitución representa una fachada formal-legal que puede coexistir con

2 Para el periodo aquí tratado cf. algunos títulos teóricamente muy interesantes: Fritz René Allemann, Macht und Ohnmacht der Guerilla (Poder e impotencia de la guerrilla), Munich: Piper 1974; Richard E. Kiessler, Guerilla und Revolution. Parteikommunismus und Partisanenstrategie in Lateinamerika (Guerrilla y revolución. Comunismo de partido y estrategia guerrillera en Latinoamérica), Bonn: Neve Gesellschaft 1975; Robert F. Lamberg, Die Guerillas in Lateinamerika. Theorie und Praxis eines revolutionaren Modells (Las guerrillas en Latinoamérica. Teoría y praxis de un modelo revolucionario), Munich: dtv 1972; Gérard Chaliand, Mythes révolutionnaires du Tiers Monde. Guérillas et socialismes, París: Sevil 1979.Sobre la etapa posterior del conflicto cf. Daniel Pécaut, Guerra contra la sociedad, Bogotá: Espasa 2001; Charles Bergquist / Ricardo Peñaranda / Gonzalo Sánchez (comps.), Violence in Colombia 1990-2000: Waging War and Negotiating Peace, Wilmington: SR Books 2001.

3 Fenómenos tempranamente analizados en: Álvaro Camacho Guizado, Droga y sociedad en Colombia. El poder y el estigma, Bogotá: CIDSE / CEREC 1988, pp. 37-58; Alejandro Reyes Posada, La violencia y la expansión territorial del narcotráfico, Bogotá: Universidad Nacional de Colombia, pp. 23-27 [tiposcrito multicopiado]; Ibán de Rementería, Hipótesis sobre la violencia reciente en el Magdalena Medio, en: Gonzalo Sánchez / Ricardo Peñaranda (comps.), Pasado y presente de la violencia en Colombia, Bogotá: CEREC 1986, pp. 333348.

4 Eduardo Pizarro Leongómez, Insurgencia sin revolución. La guerrilla en Colombia en una perspectiva comparada, Bogotá: Tercer Mundo / IEPRI 1996, p. XXIII.- Esta brillante obra reúne de modo ejemplar las cualidades positivas aludidas en el primer párrafo de este texto. 
una realidad muy distinta, pero esta constitución y su largo proceso constituyente dan cuenta de un amplio proceso modernizador en el ámbito político y jurídico, que alcanza a sectores poblacionales bastante dilatados y mejor educados que en generaciones anteriores, los que, a su vez, se identifican con el Estado Social de Derecho, aprecian un amplio catálogo de derechos y garantías y aprueban la complementación de la democracia representativa con instrumentos de la democracia participativa. Estos sectores, sobre todo urbanos, se adhieren a valores normativos de tipo moderno y hasta cosmopolita, y no se sienten atraídos por las pautas reiterativas de comportamiento de los movimientos guerrilleros, que representan una dimensión premoderna, marcadamente tradicionalista e innecesariamente violenta para la sensibilidad contemporánea ${ }^{5}$.

\section{Aspectos del ejercicio de la violencia vinculados a la cultura política tradicional}

Aquí se usará un concepto relativamente corriente de violencia: se la percibe primordialmente como la renuncia a la comunicación con los otros, renuncia que incluye la probabilidad de una confrontación corporal inmediata. Se manifiesta en el intento de hacer realidad las pretensiones y expectativas definidas unilateralmente. Desde la propia perspectiva de los movimientos guerrilleros, su praxis representa una forma de uso inmediato de violencia con un cierto efecto social, basado en una renuncia a la lealtad hacia el Estado respectivo y en el rechazo del diálogo político, por lo menos en sus momentos más intensos ${ }^{6}$. Puesto que este texto trata de reconstruir algunos rasgos centrales de la cultura de la violencia, dejo de lado importantes aspectos como la periodización de la misma, la tipología de los movimientos integrantes, la cantidad de víctimas y la descripción de las dirigencias guerrilleras ${ }^{7}$.

Casi todos los estudiosos de nuestro tema perciben los comienzos de la actividad guerrillera del siglo XX en los núcleos de autodefensa campesina a partir aproximadamente de 1948, cuyas metas programáticas - si se puede hablar de ello - se reducían al postulado de una reforma agraria (sin una concepción muy precisa), una protección efectiva contra las arbitrariedades de los latifundistas y los policías, el fortalecimiento de la economía campesina y una participación política adecuada. A lo largo de un enrevesado proceso, el grupo más importante de aquellas autodefensas se transformó en las Fuerzas Armadas Revolucionarias de Colombia (FARC),

5 Ibid., pp. 89-138 (con abundantes datos empírico-documentales sobre la pérdida de atracción de las guerrillas rurales - a menudo de orientación foquista-guevarista - sobre estratos urbanos, grupos juveniles y ámbitos universitarios).

- Sobre definiciones de la violencia y las causas de la misma en Colombia cf. el dilatado estudio, basado en datos empírico-documentales, de Fernando Gaitán Daza, Una indagación sobre las causas de la violencia en Colombia, en: Malcolm Deas / Fernando Gaitán Daza, op. cit. (nota 1), pp. 87-406, especialmente pp. 96-111, 181-186.

7 Para la tipología cf. Eduardo Pizarro Leongómez, op. cit. (nota 4), pp. 57-64; para las otras temáticas cf. Peter Waldmann, Guerra civil, terrorismo y anomia social. El caso colombiano en un contexto globalizado, Bogotá: Norma 2007, pp. 242-247; Peter Waldmann, Strategien politischer Gewalt (Estrategias de violencia política), Stuttgart etc.: Kohlhammer 1977, pp. 14-18, 24-27. 
que adoptaron esta denominación en 1964. Poco después el Partido Comunista de Colombia, de forma ambigua, las declaró su brazo armado8. Con el paso de los años estos objetivos se mezclaron con formas de bandolerismo rural convencional, con pequeños ejércitos privados irregulares y hasta con elementos incipientes de una lucha de clases, y en las últimas décadas con mecanismos muy refinados de protección a los cultivadores de coca y de participación en el narcotráfico?. Puesto que todos estos temas han sido analizados exhaustivamente por autores colombianos y extranjeros 10 , aquí me limitaré a algunos aspectos que me parecen relevantes por conformar factores muy resistentes al cambio, que pertenecen a las convenciones y rutinas más sólidas de la cultura política del país y que son reproducidos - a menudo inconscientemente - por radicales, socialistas y populistas como si fueran elementos positivos del propio acervo revolucionario.

Uno de los motivos para el movimiento guerrillero se lo puede hallar en los aspectos socio-psicológicos, en las concepciones habituales sobre la historia y en las normas colectivas que determinan los esquemas mentales en los que se han movido los guerrilleros colombianos y sus simpatizantes académicos, y que se manifiestan en el modo cómo estos se rebelan contra lo establecido... si es que se rebelan realmente contra el orden establecido. La combinación de estos elementos con ideales social-revolucionarios y con una tradición específica del uso de la fuerza ha suministrado probablemente el fundamento del cual han surgido los movimientos guerrilleros. La lucha guerrillera no es sólo una vía básicamente militar y violenta hacia la conquista del poder político, sino también una filosofía específica de la vida, que reúne en sí formas marcadas de los valores tradicionales de comportamiento y que, por ende, descubre involuntariamente algunos rasgos de lo que estos movimientos se imaginan sobre el anhelado orden nuevo. Este último se manifiesta como la reiteración de rutinas y convenciones que vienen de muy atrás, pero remozadas según las modas del día. Estas últimas se exhiben en la liturgia anti-imperialista y en las curiosas consignas socialistas y utopistas. Estas metas se fundamentan en

\footnotetext{
8 Sobre el origen, los años formativos y la evolución ulterior de las FARC cf. Eduardo Pizarro Leongómez, Las FARC (1949-1966). De la autodefensa a la combinación de todas las formas de lucha, Bogotá: Tercer Mundo / IEPRI 1991; Eduardo Pizarro Leongómez, Las FARC 19492011. De guerrilla campesina a máquina de guerra, Bogotá: Norma 2011 , passim.

9 Cf. el temprano estudio: Fernando Cubides / Jaime Jaramillo / Leónidas Mora, Colonización, coca y guerrilla, Bogotá: Universidad Nacional de Colombia 1986.

10 Sobre la violencia del periodo aquí tratado existe una literatura muy amplia. Entre muchos otros títulos cf. Germán Castro Caycedo, Colombia amarga, Bogotá: Valencia 1977; Paul Oquist, Violencia, conflicto y política en Colombia, Bogotá: BBP 1978; Richard Maullin, Soldiers, Guerillas, and Politics in Colombia, Lexington: Heath 1973; Germán Guzmán Campos et al., La violencia en Colombia, Bogotá 1980 (2 vols.); James D. Henderson, Cuando Colombia se desangró. Un estudio de la violencia en metrópoli y provincia, Bogotá: El Áncora 1985; Francisco Posada, Colombia: violencia y subdesarrollo, Bogotá: Universidad Nacional de Colombia, 1969; Camilo Echandía, El conflicto armado y las manifestaciones de violencia en las regiones de Colombia, Bogotá: Presidencia de la República / Oficina del Alto Comisionado para la Paz 1999.
} 
la concepción de que la realidad latinoamericana exige una solución socialista, que esta última es sencillamente inminente y que puede ser puesta en práctica por un grupo de revolucionarios profesionales decididos. Las organizaciones guerrilleras han presupuesto que la estructura social colombiana era básicamente injusta y que ha ejercido una violencia permanente e insoportable sobre las capas subalternas de la población. La violencia de las guerrillas debía entonces ser vista como una contraviolencia totalmente justa: un fenómeno universalmente legitimado. Colombia sería sólo un caso ejemplar de un desarrollo planetario ${ }^{11}$.

Según una publicación cercana a las FARC, la violencia ejercida por el movimiento guerrillero representaría solamente la resistencia armada popular contra la explotación secular sufrida por los campesinos ${ }^{12}$. El teorema de la contra-violencia se complementa casi siempre con otro elemento tradicional de los propios actores, proveniente de raíces muy profundas, casi siempre obvias y sobreentendidas y por ello nunca analizadas por ellos mismos: el culto de la valentía y la virilidad y el desprecio concomitante por la actividad racional que sopesa cuidadosamente aśpectos positivos y negativos de toda decisión. En la vida cotidiana de la guerrilla esta mentalidad se manifestaba en la celebración positiva de todo combate armado, que era considerado como el auténtico éxtasis del verdadero guerrillero ${ }^{13}$. En este contexto todo intercambio de disparos era visto como una muestra de la alegría, el ánimo, el entusiasmo y el optimismo de los guerrilleros ${ }^{14}$. La existencia diaria en el frente de combate habría sido dura y sacrificada, pero al mismo tiempo pura, justa y cultivada [sic]. La presencia de mujeres en los frentes guerrilleros representaría una hermosa recompensa para los esforzados guerreros ${ }^{15}$. Aquí se hallan reunidos algunos lugares comunes muy vigorosos del legado ibero-católico.

La concepción misma de contra-cultura y contra-violencia pertenece a los patrones explicativos de carácter dicotómico y simplificador. En Colombia, como en numerosos países del Tercer Mundo, se daría de modo permanente la contraposición entre una pequeña oligarquía de privilegiados y una enorme masa de desposeídos 16 . Esta figura de origen

\footnotetext{
11 Esta es la argumentación de Peter Mossmann, Campesinos und Ausbeutungsstrukturen im internationalen Konfliktpotential. Das kolumbianische Beispiel (Campesinos y estructuras de explotación en el potencial internacional de conflictos. El ejemplo de Colombia), Saarbrücken / Fort Lauderdale: Breitenbach 1979, pp. 6-10.

12 Nicolás Buenaventura et al., Tregua y Unión Patriótica, Bogotá: CEIS 1985, p. 12, 65.

13 Concepto atribuido a Jacobo Arenas, uno de los principales ideólogos de las FARC, citado en: Carlos Arango, FARC. Veinte años. De Marquetalia a La Uribe, Bogotá: Autora 1984, p. 19.- Cf. también: Jacobo Arenas, Cese al fuego. Una historia política de las FARC, Bogotá: Oveja Negra 1985.

14 Carlos Arango, op. cit. (nota 13), p. 42.

15 Ibid., p. 20.

${ }^{16}$ Cf. entre otros títulos: Álvaro Echeverri Uruburu, Élites y proceso político en Colombia. Una
} 
bíblico y, por lo tanto, muy afincada en la memoria popular, no es adecuada a la complejidad social y cultural que desarrolló la sociedad colombiana desde el siglo XVIII, en la cual no se puede constatar la confrontación única y permanente de dos clases antagónicas entre síl7. De acuerdo a la argumentación de Daniel Pécaut, el origen y las manifestaciones de la violencia colombiana no pueden ser comprendidas mediante explicaciones monocausales que reducen todo a la mencionada lucha de clases de índole dicotómica ${ }^{18}$. Por otra parte, desde un principio se podía comprobar un factor proclive a la acción violenta, factor que se extendía a todos los estratos sociales y grupos étnicos del país y que a menudo no tenía una utilidad instrumental para los objetivos de aquellos mismos estratos y grupos. Se puede afirmar que el movimiento guerrillero tendía a una reducción de la muy compleja realidad social mediante el uso de las armas, operación cognoscitiva habitual en sociedades premodernas para comprender una dimensión que rebasa el ámbito de las intuiciones y emociones.

La concepción misma de la contra-violencia - la responsabilidad pertenece, en última instancia, a los otros ${ }^{19}$-, la retórica de los movimientos guerrilleros, sus estructuras y jerarquías internas y, ante todo, sus valores implícitos de orientación (es decir: sus códigos paralelos de conducta, nunca explicitados, pero siempre vigentes) representan convenciones y rutinas que vienen de muy atrás y que eran compartidas por una buena parte de la población colombiana. Por ello se explica, por lo menos parcialmente, la popularidad de que gozaron los movimientos guerrilleros en la Colombia premoderna y la "comprensión" hacia ellos que exhibieron numerosos intelectuales, progresistas en sus opiniones políticas y conservadores en su dimensión axiológica profunda. Y, por otra parte, esta cultura política tradicional configura la clave para entender la desproporcionalidad que siempre se dio entre los medios violentos usados persistentemente por estos movimientos y la modestia de sus fines programáticos. Este tema, ciertamente incómodo para la opinión pública

democracia principesca y endogámica, Bogotá: Fundación Universitaria Autónoma de Colombia 1987, pp. 23-30; Amparo Cadavid et al., Colombia: conflicto social y violencia 1980-1988, Bogotá: CINEP 1988; Ignacio Torres Giraldo, Los inconformes. Historia de la rebeldía de las masas en Colombia, Bogotá: Margen Izquierdo 1972-1973 (3 vols.).- Algunos elementos similares en: Gonzalo Sánchez / Donny Meertens, Bandoleros, gamonales y campesinos. El caso de la violencia en Colombia, Bogotá: El Áncora 1983, passim.

17 Daniel Pécaut, L'ordre et la violence. Évolution socio-politique de la Colombie entre 1930 et 1953, París: EHESS 1987, pp. 370-379, 384-385, 387-391.

18 lbid., pp. 335-338.

19 La vía armada es impuesta al movimiento M-19 por la oligarquía, "Ia antipatria": El M-19 no renuncia a su lucha por la democracia (comunicado de la dirección del M-19 del 1 de junio de 1982, firmado por Jaime Bateman Cayón), en: COLOMBIA (Bogotá), № 4, junio de 1982, p. 16. 
intelectual, es lo que trato de explicitar en este ensayo.

Cuanto más sencilla y más fácil de comprender es una teoría y la solución pertinente, tanto menos discusiones o controversias surgirán en torno a sus principios y tanto más fuerte será la posición de la jefatura. Esquemas de pensamiento exentos de complicaciones se adaptan muy bien a jerarquías claras de comando y acatamiento; si son aceptados, se va formando una conducta dirigida principalmente a la obediencia y la subordinación. En un medio básicamente tradicional - y el mini-universo de la guerrilla es uno de ellos - las autoridades disfrutan del hecho de que la masa de la población afectada no dispone todavía de la facultad de ejercer una actitud crítica con respecto a sus "superiores".

La simplicidad de los esquemas de pensamiento se hace manifiesta igualmente en la adopción de prejuicios habituales y muy antiguos, cuya difusión y popularidad han impedido hasta ahora un cuestionamiento crítico de los mismos. Se piensa que los países latinoamericanos disponen de recursos inagotables para el desenvolvimiento económico y que tanto la perfidia imperialista como el desinterés de la clase alta han obstaculizado su utilización racional. Jaime Arenas ${ }^{20}$ afirmó que la gente se muere de hambre en uno de los países más fecundos y ricos del continente, y esta suposición mal comprobada es usada en toda América Latina para justificar salidas políticas radicales. Por otra parte, las soluciones globales propugnadas por los partidarios de la guerrilla se distinguen por la pobreza de su contenido: se trata, por ejemplo, de una toma de partido por el modelo cubano de socialismo estatista dictada por los sentimientos, creyéndose que mediante esto se solucionarán todos los problemas del desarrollo. Para un examen crítico de la mentalidad prevaleciente en los movimientos guerrilleros resultan ser de capital importancia las presuposiciones y las precondiciones que adquirieron el valor de obvias, es decir: de naturales. Hay que señalar que casi todas las declaraciones de los diversos grupos guerrilleros y de sus pensadores se han distinguido por el carácter definitivo que atribuyen a la "crisis insoluble" de las sociedades latinoamericanas. La revolución socialista ha sido percibida como históricamente "necesaria". La crisis del orden existente y, sobre todo, la inminencia de una situación ya revolucionaria no eran las conclusiones de un análisis cuidadoso, sino los puntos de partida de toda argumentación. Un pensamiento, que está determinado hasta tal grado por lo obvio, denota una afinidad notoria con respecto a sistemas dogmáticos y se inclina irremediablemente al fomento de pautas autoritarias de comportamiento y a imposibilitar normas democráticas.

20 Jaime Arenas, La guerrilla por dentro. Análisis del ELN colombiano, Bogotá: Tercer Mundo 1971, p. 14. 


\section{Los rasgos tradicional-conservadores bajo el manto de lo revolucionario}

La reducción cognoscitiva por las armas es una de las formas relativamente usuales de conseguir un sentido general que aclare la posición y la identidad de personas y grupos en sociedades que se hallan en un proceso acelerado de modernización, es decir: de un aumento inesperado de la complejidad social y cultural. Desde mediados del siglo XX, esta última, como en el resto del mundo, promovió en Colombia una cierta pérdida de los lazos primarios. Los movimientos guerrilleros, paradójicamente, intentaban también recuperar los vínculos de solidaridad inmediata que los procesos de urbanización y modernización empezaban a diluir. Esta recuperación adquiere a menudo rasgos paternalistas, propios del orden social premoderno, que se manifiestan en el tratamiento de las masas, a las que habría que movilizar desde arriba. Las formas rutinarias de la lucha armada de las guerrillas, sobre todo si esta transcurre de victoria en victoria, representarían uno de los mejores procedimientos de movilización. El pueblo colombiano, afirmó uno de los líderes principales del M-19, Jaime Bateman Cayón, no se deja impresionar por palabras y discursos, sino por el lenguaje de los hechos ${ }^{21}$. Esta ideología paternalista apelaba incansablemente a figuras de la retórica convencional, como el patriotismo de los colombianos, la dignidad de la nación, los intereses vitales del pueblo, la responsabilidad histórica de la juventud y el objetivo de una vida mejor, más digna y plena de futuro22, mientras al mismo tiempo las metas socio-económicas del M-19 a mediano y largo plazo permanecían en una nebulosa sintomática. Estos conceptos eufónicos tocan ciertamente fibras emotivas y profundas de todas las sociedades latinoamericanas, pero resultan inoperantes para diseñar políticas públicas concretas.

Los revolucionarios de profesión se sienten obligados a explicar a las masas una y otra vez sus ideas y decisiones, que, según ellos, son las únicas que pueden tener éxito. Significativamente el "trabajo político" ya fue definido por Ernesto Che Guevara como el intento de "explicar" a las masas las indicaciones de arriba, hasta que estas las consideren como propias ${ }^{23}$. La iniciativa de la dirección de la guerrilla o del partido resulta así la mejor

21Who's in Control (entrevista con Jaime Bateman Cayón), en: NACLA Report on the Americas, vol. XVII, № 3, mayo-junio de 1983, pp. 26-27; cf. también Enrique Neira, Un caso intrincado de violencia: Colombia, en: NUEVA SOCIEDAD (Caracas), NN 105, enero-febrero de 1990, pp. 142-151.

22 El M-19 a todos los colombianos, en: Patricia Lara, Siembra vientos y recogerás tempestades, Bogotá: Punto de Partida 1982, pp. 182-184.- Utilizando una expresión habitual en América Latina, los dirigentes del M-19 aseveraron con frecuencia que la lucha armada debería proseguir "hasta las últimas consecuencias", porque esto sería lo que el pueblo espera. Eduardo Pizarro calificó al M-19 como el "Apocalipsis alegre" (Pizarro Leongómez, Insurgencia..., op. cit. [nota 4], p. 84).

${ }^{23}$ Ernesto Che Guevara, El socialismo y el hombre en Cuba, en: Ernesto Che Guevara, Obra revolucionaria (compilación de Roberto Fernández Retamar), México: Era 1967, passim. 
imaginable y la más adecuada a los intereses populares. Pero también en los casos en que no se subraya la infalibilidad del gremio rector, la distribución del saber y de la facultad decisoria -y, por tanto, del poder en sentido enfático - queda evidentemente desplazada a favor de la dirección. Las masas son concebidas como un fenómeno más bien amorfo, que poseen a veces ocurrencias e informaciones valiosas, pero que no tienen la facultad de diseñar las grandes líneas de la estrategia a largo plazo, no disponiendo de los conocimientos necesarios acerca del decurso de la historia universal. Los gremios dirigentes de las guerrillas nunca pusieron en cuestión su privilegiada posición dentro del movimiento respectivo. Debido a una pretendida superioridad en conocimientos y en facultad decisoria con respecto a sus miembros sencillos y a la totalidad de las masas no-privilegiadas, los líderes insistieron continuamente en sus derechos a comandar. La dirigencia provenía de los estratos medios urbanos y la masa de los combatientes de las clases subalternas de origen rural24. La primera poseía el monopolio de todas las decisiones importantes y la segunda tenía el sagrado deber de la obediencia. La consecuencia de todo esto fue una cierta reproducción del orden social que las guerrillas decían combatir: el mini-universo de estos movimientos ha sido tan conservador en el ámbito axiológico, tan rutinario en el plano logístico y tan convencional en su retórica como la sociedad colombiana de mediados del siglo XX.

La fe apenas relativizada en la ortodoxia de la propia misión de mejorar el mundo se correlaciona con un dogmatismo fundamental, con una actitud elitista con respecto a las instancias inferiores de la organización y con un tratamiento paternalista de las masas dependientes. Tanto los críticos como antiguos participantes del movimiento guerrillero han llamado la atención hacia el nexo de compasión y autoritarismo existente entre los guerrilleros y los campesinos. Refiriéndose al Ejército de Liberación Nacional (ELN), Jaime Arenas escribió que la guerrilla en Colombia tuvo que impregnar a los campesinos la consciencia de clase correcta, para que estos comprendieran por fin su propia situación ${ }^{25}$. Quién mandaba y quién obedecía estaba claro en todos los grupos desde un comienzo. La autovaloración excesiva de los dirigentes, la aceptación de un ordenamiento estrictamente jerárquico y el tinte voluntarista de todas las acciones se han mezclado con las pautas tradicionales de comportamiento en forma muy peculiar, dando origen a elementos de índole inequívocamente totalitaria. El dogmatismo, el celo sectario y las imágenes irracionales de autoridad y

\footnotetext{
24 De acuerdo a Peter Waldmann, hay una notable similitud entre los combatientes de bajo rango de las guerrillas y aquellos que pertenecen a los escuadrones de la extrema derecha: varones jóvenes, solteros, de origen provinciano-rural, carentes de trabajo y con un nivel educacional muy modesto. Waldmann, Guerra civil..., op. cit. (nota 7), p. 259.

25 Jaime Arenas, op. cit. (nota 20), p. 43.- Desde otra perspectiva cf. Ricardo Lara Parada / Oscar Castaño, El guerrillero y el político, Bogotá: Oveja Negra 1984.
} 
dominación, prevalecientes en estas agrupaciones, tienen mucho que ver con una mentalidad conspirativa convencional.

A causa de la superficialidad y pobreza de sus enfoques teóricos, los partidarios de la guerrilla son proclives a castigar las más mínimas divergencias de opinión con la mayor severidad y a considerar ideas discrepantes como herejías dignas de condenación. Estas últimas alcanzan la categoría de las faltas más graves. La libertad de crítica ha sido equiparada en todos los tiempos con el cuestionamiento de las estructuras jerárquicas del poder, y los detentadores de este no le han tenido simpatía. En último término también en el mini-universo de la guerrilla se trata de mantener ciertas estructuras dominacionales, y esto ocurre en un ambiente de dogmatismo, violencia inmediata y expectativas apocalípticas. Esta constelación ha fomentado fenómenos como la intolerancia, la rigidez jerárquica y la mentalidad de súbdito, que pertenecieron a la vida diaria colombiana, pero que fueron conservadas en el mundo guerrillero bajo un barniz de revolución social. En algunos grupos esto ha conducido a que las diferencias de opinión hayan sido "arregladas" con el fusilamiento de los disidentes y con la persecución rigurosa de los sobrevivientes que mantenían sus ideas heterodoxas. El ELN alcanzó una triste celebridad a causa de la "disciplina" imperante en sus filas. El número de sus miembros, que han pagado con la vida su desviación de la línea general, no fue precisamente muy bajo26, pero muchas de estas víctimas estaban convencidas de la corrección de las medidas tomadas por el tribunal de honor y se ofrecieron voluntariamente a cavar la propia tumba poco antes del fusilamiento27. Obediencia, perseverancia, sumisión y diligencia se convirtieron entonces en valores de orientación positivos, confirmados por las presuntas necesidades de la situación militar. Todos los grupos guerrilleros fueron proclives al establecimiento de tribunales severos y de castigos duros para sancionar faltas y omisiones ${ }^{28}$. Cuando la obediencia militarizada se transforma en una virtud central, entonces queda poco espacio para el florecimiento efectivo de procedimientos democráticos. Los movimientos guerrilleros colombianos se opusieron a una "democracia discutidora" y se decantaron por la prioridad de los puntos de vista militares. Se puede afirmar que la disciplina convencional reemplazó toda forma de democracia en los movimientos guerrilleros; las discusiones internas eran prácticamente desconocidas y serían sencillamente inconcebibles en las instancias inferiores.

26 Jaime Arenas, op. cit. (nota 20), pp. 46, 52-53, 59, 112, 124, 136, 149, 152, 160, 175-176; Jaime Arenas, Dans la guérilla, París: Calmann-Lévy 1972, pp. 13-14, 46, 57, 148, 174-178, 203, 235, 254. (Se trata de dos textos similares, pero no idénticos.)

27 Jaime Arenas, La guerrilla..., op. cit. (nota 20), p. 130.

28 Jaime Arenas informa exhaustivamente sobre los privilegios de los jefes, la dureza de los castigos, la falta de solidaridad entre los miembros de la organización y el énfasis en las virtudes tradicionales (ibid., [nota 20], pp. 120, 125, 136-138, 159-161). 
Como resumen se puede afirmar que los líderes reprodujeron en los movimientos guerrilleros la atmósfera de intolerancia y dogmatismo que había sido habitual en buena parte de la sociedad colombiana. Estas personas se distinguieron además por su ansia convencional por el poder, por su afán desmedido de publicidad y por su paternalismo autoritario frente a los simples soldados de la organización respectiva ${ }^{29}$. Malcolm Deas señaló acertadamente que el anhelo de publicidad entre los líderes del M-19 aludía al verdadero objetivo de estas personas: el ascenso social y la aspiración de ejercer el poder político, lo que, paradójicamente, se vinculaba a un enorme talento de improvisación, sobre todo para aquello que requería de "astucia y malicia"30. Los dirigentes de todas las guerrillas no han sido proclives a convivir y menos a debatir con los que pensaban de modo diferente. Este contexto fue muy marcado en el ELN 31 , en el maoísta Ejército Popular de Liberación (EPL) 32 y hasta en el Movimiento Revolucionario Quintín Lame, que decía representar a los indígenas Páez de la región del Cauca, y cuyas arbitrariedades no fueron menores a las de los otros movimientos guerrilleros 33 .

\section{La violencia se vuelve autónoma}

El movimiento guerrillero colombiano se ha destacado por una forma particular del autoritarismo elitario, que engloba la utilización intensa de violencia física inmediata. Se trataba de la tendencia a la militarización de toda la lucha revolucionaria: Ios teóricos de la guerrilla rural han hecho un significativo aporte a la tecnificación de la guerrilla en el sentido de emprender y evaluar todas las actividades y medidas de la organización según el criterio de la efectividad militar. La militarización de la lucha política permite reconocer un cierto modo de la utilización de la violencia, que

29 Fritz René Allemann analiza la propensión al prestigio y la manía publicitaria de los jefes, que no estaban en relación alguna con el modesto resultado de sus acciones. Cf. Allemann, op. cit. (nota 2), pp. 206, 209-210, 214.

30 Malcolm Deas, Canjes violentos..., op. cit. (nota 1), pp. 46-47, 57-58 El M-19 "no pudo comunicar un mensaje porque no tenía mensaje, sólo estilo" (ibid., p. 58).- Sobre el trasfondo de la carencia de verdaderos motivos revolucionarios en el $\mathrm{M}$-19 cf. también el brillante texto de Malcolm Deas, Un día en Yumbo y Corinto: 24 de agosto de 1984, en: Malcolm Deas, Del poder y la gramática y otros ensayos sobre historia, política y literatura colombianas, Bogotá: Tercer Mundo 1993, pp. 313-328, especialmente p. 328.

31 Cf. el testimonio de uno de los líderes más importantes: Alonso Ojeda Awad, El ELN. Itinerario de una lucha, en: Olga Behar (comp.), Las guerrillas de la paz, Bogotá: Planeta 1985, pp. 51-67, especialmente p. 60.

32 Sobre el EPL cf. Faviola Calvo, EPL: diez hombres, un ejército, una historia, Bogotá: ECOE 1985, pp. 121-125; Richard Maullin, op. cit. (nota 10), pp. 48-53.

33 Sobre Quintín Lame cf. Eduardo Pizarro Leongómez, Insurgencia..., op. cit. (nota 4), pp. 60, 70-71, 253-255. 
prolonga algunos elementos del legado ibero-católico, del caudillismo latinoamericano y del comportamiento anómico de protesta ${ }^{34}$. La tradición latinoamericana es muy rica en fenómenos del uso inmediato de la violencia y muy pobre en procedimientos de la regulación pacífica de conflictos y en la resolución negociada de intereses contrapuestos, así que la guerra de guerrillas ha proseguido una vieja y bien enraizada tendencia. Por otra parte, la estructura interna de la guerrilla, tanto en sus variantes rurales como urbanas, se basaba en un orden estrictamente jerárquico, que consiste, en analogía al partido de tipo leninista, en un eslabonamiento de mando inequívoco de arriba hacia abajo. Esta jerarquía piramidal conllevaba la atribución de los más amplios poderes y de toda clase de privilegios al gremio rector, mientras que a las masas les tocaba la responsabilidad de llevar a la práctica las decisiones de la autoridad revolucionaria.

En muchas sociedades premodernas se asume que la utilización generosa de la fuerza física representa una alternativa positiva en lo referente a la solución de los conflictos sociales. En Colombia los movimientos guerrilleros han actuado siempre bajo la premisa tácita - pero fuertemente arraigada - de que el uso de la violencia física contribuiría a que las masas urbanas y rurales iban a reconocer en ellos su propia vanguardia. Esta "filosofía de la acción" deja reconocer un activismo voluntarista, enlazado, por un lado, con la tradición ibero-católica, y, por otro, con la teoría leninista en torno al funcionamiento del partido socialista. Uno de los rasgos fundamentales de la concepción activista-voluntarista consiste en una relativa desatención de las condiciones objetivas y en una sobrevaloración correspondiente de la propia actuación. Por tanto, la lucha misma de los rebeldes crearía las condiciones de la revolución cuando estas no estén dadas aún. Al foco guerrillero inicial y estrictamente delimitado se le atribuye la capacidad de modificar las circunstancias sociales y políticas de manera inmediata, duradera e irrevocable y en dirección a un agravamiento revolucionario de la situación. En la mayoría de los casos, esta concepción ha demostrado ser completamente insostenible.

La combinación de culto al dirigente con dogmatismo contribuye al renacimiento del caudillismo latinoamericano y a la consolidación de una élite de comando, que en la praxis no debe justificarse ante nadie y que toma

\footnotetext{
34 Notables pensadores colombianos, como Orlando Fals Borda, han justificado este conjunto como el "derecho a la rebelión justa". Cf. Orlando Fals Borda, Las revoluciones inconclusas en América Latina 1809-1968, México: Siglo XXI 1968, p. 49.- Este autor concibe al movimiento guerrillero como una corriente de protesta social, que reúne en sí elementos subversivos y utópicos y que actúa como una contra-violencia con funciones presuntamente emancipatorias e igualitarias.
} 
una postura paternalista frente a las instancias inferiores ${ }^{35}$. Esta tendencia a la glorificación personalista de los jefes está correlacionada con el estilo dramático y sentimental de todas las declaraciones de la guerrilla, con una actitud moralizante frente a los problemas políticos, con la idea del heroísmo diario como contenido de la vida y con la adopción de pautas de comportamiento irracionales y atávicas para los asuntos cotidianos ${ }^{36}$. Han sido justamente los partidarios de la guerrilla rural los que incurrieron en una idealización romántica de la vida sencilla del campo, áspera pero varonil, y en un desprecio vasto de la cultura urbana. Esta actitud romántica y voluntarista fue enriquecida por medio de elementos provenientes de las tradiciones premodernas. El ensalzamiento del heroísmo, la recomendación de valores de orientación de índole biologista y la idealización generalizada de la violencia tomaron un lugar central como criterios para la selección de dirigentes. Los débiles podían ser vistos a menudo como contrarrevolucionarios. La facultad crítica de evaluación, los conocimientos específicos y hasta las convicciones profundas no representaron nunca criterios de selección para las élites dirigentes.

Este menosprecio de aspectos racionales prolonga la tradición latinoamericana del culto al héroe, que, a su vez, es inconcebible sin su génesis hispano-católica. Este culto, rico en palabras y gestos, se basa en una idea atávica del honor y está dirigido a acontecimientos momentáneos y muy rara vez a una perspectiva de largo plazo. Está entremezclado con el melodrama y la manía publicitaria. La cercanía a la muerte, y hasta su idealización y glorificación, han determinado los valores preconscientes y, por lo tanto, muy profundos de la ética guerrillera. Para Orlando Fals Borda es la comprobación de la "vitalidad" de las sociedades latinoamericanas en sus esfuerzos por el progreso y la autorrealización ${ }^{37}$. Esta concepción de violencia puede conducir fácilmente a exaltar la utilización inmediata y recurrente de la fuerza física como si esta fuese un factor enteramente positivo, transformándose en un mito desprendido de la realidad social, cuya fascinación parece debilitar todos los criterios racionales 38 .

35 Jaime Arenas, La guerrilla.... op. cit. (nota 20), p. 133, 135; cf. también el excelente texto de Enrique Valencia, Notas para una sociología de la guerrilla, en REVISTA MEXICANA DE sociología (México), № 2, vol. 32 (1970), pp. 335-355.

36 Jaime Arenas, Dans la guérilla, op. cit. (nota 26), pp. 13-14, 46, 57, 148, 174, 175-178, 188-

195, 203, 235, 254.

37 Orlando Fals Borda, op. cit. (nota 34), p. 50.

38 Sobre las motivaciones de los jóvenes para unirse a los movimientos guerrilleros cf. la bien documentada obra de Yolanda Zuluaga, Pourquoi de jeunes colombiens se rebellent et choisissent la voie des armes, París: EHESS 1988; María Victoria Uribe, Antropología de la inhumanidad. Un ensayo interpretativo sobre el terror en Colombia, Bogotá: Norma 2004.Cf. también opiniones distintas en: Gonzalo Sánchez et al., Colombia: violencia y democracia. Informe presentado al Ministerio de Gobierno, Bogotá: Universidad Nacional de Colombia 1987; Álvaro Camacho (comp.), La Colombia de hoy. Sociología y sociedad, 


\section{Coda provisional}

Los datos y argumentos hasta aquí expuestos tienen por objetivo mostrar la desproporción entre la modestia político-programática de las metas propugnadas por los movimientos guerrilleros y la magnitud de los esfuerzos técnico-militares emprendidos para alcanzar esos fines ${ }^{39}$. Peter Waldmann lo explicitó claramente: "Con frecuencia, no existe la menor relación entre los medios y el fin"40. Esto tuvo dos secuelas a largo plazo: (1) la violencia empleada cotidianamente por las diferentes guerrillas se independizó de las metas primigenias de carácter más o menos radical y socialista; y (2) paulatinamente los movimientos guerrilleros se transformaron en maquinarias militares que buscaban objetivos tradicionales y rutinarios: dinero y poder. La similitud con el bandolerismo convencional salta a la vista. La explotación de los recursos económicos en los territorios que dominaban militarmente se realizó bajo las formas más diversas; en este sentido las guerrillas exhibieron un curioso potencial inventivo.

Algunos ejemplos pueden contribuir a aclarar la desproporcionalidad que acompañó a los movimientos guerrilleros colombianos desde su inicio. En el Manifiesto de Simacota (1965) el ELN propugnaba "la unidad de campesinos, obreros, estudiantes, profesionales y gentes honradas" en favor de una meta normativa final, que fue caracterizada como "Colombia una patria digna para los colombianos honestos"4l. La terminología del manifiesto puede ser calificada de radical (el documento se cierra con las palabras: "Liberación o muerte"), pero esta (la patria digna) es la única referencia clara a un futuro por el cual se deben emprender todos los sacrificios. El ELN nunca ha podido explicar cómo se vincula racionalmente la extraordinaria violencia de su ya larga praxis militar con objetivos políticos moderados que suscribiría cualquier partido reformista ${ }^{42}$. El M-19 llegó a aseverar que la propiedad privada no es la raíz de todos los males socio-económicos y era hora de regresar a la competencia económica libre y a la "defensa" de las empresas medianas y pequeñas ${ }^{43}$. En su documento programático más elaborado las FARC

Bogotá: CEREC / CIDSE 1986; Gustavo Gallón Giraldo, La república de las armas, Bogotá: CINEP 1983.

39 Richard Maullin llamó tempranamente (1973) llamó la atención sobre esta incongruencia en las FARC: cf. Maullin, op. cit. (nota 10), p. 35.

40 Peter Waldmann, Guerra civil..., op. cit. (nota 7), p. 312.- Sobre las "grandes" acciones guerrilleras que conllevaron muchas víctimas humanas dice este mismo autor: "Las masacres son en gran parte ritos inmoladores sin valor simbólico en los cuales los sacrificadores se festejan a sí mismos y su horrible quehacer" (ibid., p. 313).

${ }^{41}$ Manifiesto de Simacota del Ejército de Liberación Nacional de Colombia (ELN), en: Eduardo Pizarro Leongómez, Insurgencia..., op. cit. (nota 4), p. 251.

42 Alonso Ojeda Awad, El ELN..., op. cit. (nota 31), p. 67 (hasta el presidente conservador Belisario Betancur es tratado aquí con mucho respeto).

43 Jaime Bateman Cayón, Oiga hermano, Bogotá: Macondo 1984, pp. 45-46; [sin autor], El 
postularon el retorno a la normalidad civil, la reforma de las "costumbres políticas", la elección directa de gobernadores y alcaldes, la vigencia irrestricta de los derechos políticos, la racionalización del aparato de justicia, una reforma agraria en el estricto marco del artículo 32 de la entonces Constitución Política del Estado, mayores inversiones para la infraestructura provincial, mejoras en los campos de la educación y la salud, la modernización de la administración pública y todo esfuerzo por crear una Colombia libre, justa y próspera ${ }^{44}$. Eran metas normativas que se encontraban en cualquier declaración programática de los partidos del gobierno.

Esta discrepancia entre las pretensiones programáticas muy moderadas de los movimientos guerrilleros y su brutal praxis militar diaria puede sugerir una interpretación que ante todo perciba en estas organizaciones el anhelo de una contra-élite de compartir el poder político supremo en Colombia sin participar en los mecanismos convencionales de la democracia representativa contemporánea, que son vistos como innecesariamente engorrosos y ajenos a las tradiciones populares premodernas. En una visión de largo plazo se puede aseverar que las guerrillas colombianas resultaron ser "un fenómeno crónico", "un componente más del paisaje político", "una insurgencia crónica" 45, como las denomina Eduardo Pizarro Leongómez, que como tales contribuyeron a consolidar las funciones coercitivas del Estado colombiano. La consolidación de valores éticos ya entonces anticuados, la glorificación de la violencia y la transformación de casi toda la lucha en un mecanismo sórdido en pro del poder y el dinero debilitan toda esperanza en un orden genuinamente emancipado. La prosaica realidad del universo guerrillero ha perpetuado la falta constitutiva de libertad de muchos sistemas socio-políticos bajo un manto revolucionario. Esta problemática no tiene un interés puramente académico, porque sin la dimensión de la libertad política y de la consciencia crítica, la abolición de estructuras y relaciones injustas no podrá superar la injusticia secular, es decir, la impotencia del individuo frente a las poderosas instancias anónimas de la economía y del Estado y su dependencia con respecto a las normas convencionales del comportamiento social.

M-19, ayer y hoy: en defensa de la pequeña y mediana industria, en: COLOMBIA (Bogotá), $N^{\circ} 4$, junio de 1982, passim.

44 Memorándum del Estado Mayor Central de las FARC-EP a la plenaria de la Comisión Nacional, en: Jacobo Arenas, Cese al fuego, op. cit. (nota 13), pp. 9-14; cf. también: $20^{\circ}$ aniversario de las FARC, en: ibid., pp. 86-88; cf. también la declaración conjunta de los movimientos guerrilleros, que se destaca por una moderación ejemplar: Coordinadora Guerrillera Simón Bolívar, Posibilidades de una salida al conflicto en Colombia, en: NUEVA SOCIEDAD (Caracas), № 117, enero-febrero de 1992, pp. 87-90.

45 Eduardo Pizarro Leongómez, Insurgencia..., op. cit. (nota 4), pp. XIX, XXII, 209-215. 
Con algunas reservas se puede afirmar que los movimientos guerrilleros colombianos han sido organizaciones que han preservado la vieja herencia de autoritarismo e irracionalismo que proviene de épocas anteriores a la modernidad democrática. Esta actitud generalizada, que se puede detectar en todas las guerrillas, junto con sus muy modestos esfuerzos teóricos, no ha sido favorable para comprender la compleja evolución del país en las últimas décadas46. Esta cultura política, por más entrañable que sea, por más enraizada que se halle en sectores izquierdistas y por más favorable que parezca ser para la formación de una identidad social sólida y original, no es un factor que haya fomentado una democracia tolerante y pluralista.

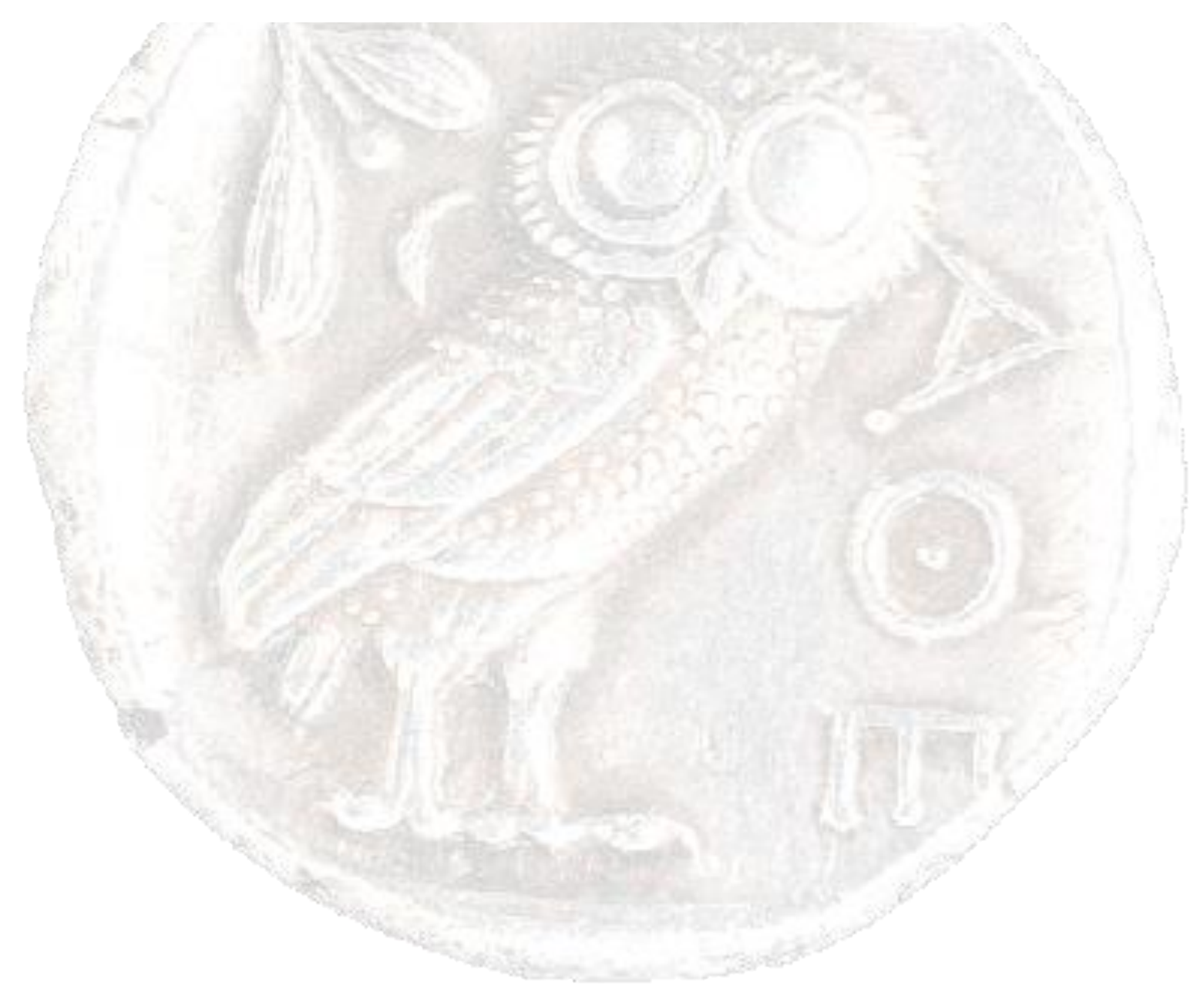

46 Para entender la complejidad del desarrollo histórico colombiano cf. Malcolm Deas, Una tierra de leones: Colombia para principiantes, en: Malcolm Deas, Del poder..., op. cit. (nota 30), pp. 329-344; Eduardo Pizarro Leongómez, Cambiar el futuro. Historia de los procesos de paz en Colombia (1981-2016), Bogotá: Debate / Penguin / Random House 2017. 